\section{Stefano Abbate}

Universidad Abat Oliba CEU, CEU Universities

sabbate@uao.es

ORCID: 0000-0002-1844-422X

DOI: http://dx.doi.org/10.12775/BPTh.2020.015

\section{Biblica}

et

Patristica

Thoruniensia

13 (2020) 3: 237-261

ISSN (print) 1689-5150

ISSN (online) 2450-7059

\title{
Continuidad de la esperanza del milenio en los primeros siglos de la Iglesia
}

\section{Continuity of the hope of the millennium in the first centuries of the Church}

\begin{abstract}
Resumen. En este artículo se pretende mostrar el desarrollo en la exégesis de Ap, 20 acerca de la posibilidad de un reino intrahistórico a partir de la noción del "milenio". Excluyendo las interpretaciones carnales y explícitamente milenaristas, especialmente con Papías de Hierápolis y luego con Ireneo de Lyon la cuestión de un milenio intrahistórico cobra fuerza. A pesar de la animadversión de Jerónimo de Estridón y Agustín de Hipona, esta se dirige en particular a las desviaciones carnales y milenaristas de algunos autores que no reflejaban fielmente la tradición de la Iglesia. En general, la posibilidad de una plenitud intrahistórica de corte espiritual ha sido apoyada o por lo menos nunca rotundamente negada en los primeros siglos de la Iglesia.
\end{abstract}

Palabras claves: Apocalipsis; milenio; Iglesia; milenarismo; reinado intrahistórico.

\begin{abstract}
This article aims to show the development in the exegesis of Rev: 20 about the possibility of an intrahistorical kingdom from the notion of the "millennium". Excluding carnal and explicitly millenarian interpretations, especially with Papias de Hierapolis and then with Irenaeus of Lyons, the question of an intrahistorical millennium gains strength. In spite of the animosity of Jerome of Stridon and Augustine of Hippo, it is directed in particular to the carnal and millenarian deviations of some authors who did not faithfully reflect the tradition of the Church. In general, the possibility of an intrahistoric plenitude of spiritual nature has been supported or at least never flatly denied in the first centuries of the Church.
\end{abstract}

Keywords: Revelation; Millennium; Church; millenarism; intrahistorical kingdom. 


\section{El milenio en la literatura cristiana de los primeros siglos}

La exégesis de Ap, 20 ha generado siempre problemas interpretativos. En este pasaje se anuncia la llegada de un milenio en el cual Satanás será atado para no tentar más a las naciones:

Luego vi a un ángel que bajaba del cielo y tenía en su mano la llave del abismo y una gran cadena. Dominó al Dragón, la serpiente antigua - que es el diablo y Satanás y lo encadenó por mil años. Lo arrojó al abismo, lo encerró y puso encima los sellos, para que no seduzca más a las naciones hasta que se cumplan los mil años. Después tiene que ser soltado por poco tiempo (Ap 20, 1-3).

Después de este acontecimiento, los mártires y los que no adoraron a la Bestia, revivieron y reinaron con Cristo mil años (Ap 20,4). Se trata de la primera resurrección que introduce a un reinado de Cristo en la tierra. Sucesivamente, al acabar los mil años, Juan relata la liberación de Satanás que intentó seducir a los santos hasta que: "bajó fuego del cielo y los devoró. Y el diablo, su seductor, fue arrojado al lago de fuego y azufre, donde están también la Bestia y el falso profeta, y serán atormentados día y noche por los siglos de los siglos" (Ap 20, 9-10). Después de la derrota del mal se producirá la segunda resurrección y la instauración de la Jerusalén celestial, donde habrá "un cielo nuevo y una tierra nueva", "la morada de Dios con los hombres" (Ap 21, 1).

A partir de este reinado milenario incluido en una realidad intrahistórica ${ }^{1}$, se han desarrollado una serie de especulaciones para entender el significado de estas palabras.

Algún eco, no siempre claro e inteligible, de la esperanza intrahistórica contenida en el milenio del reinado de los santos puede encontrarse en los textos de escritores de los Padres Apostólicos, oyentes de los apostoles. En la primera Carta de San Clemente, discípulo de Pedro y Pablo, leemos un pasaje acerca de la misericordia de Dios y de la necesidad de ser encontrados en vida llenos de caridad. Parece afirmar que los justos que serán hallados en la caridad se manifestarán en el advenimiento del Reino de Cristo:

1 Se deduce que es una realidad intrahistórica por dos razones principales: el mal sigue presente a pesar de no poder seducir el reino de los santos. Tanto es así, que sucesivamente la seducción de Satanás vuelve a aparecer por un breve periodo de tiempo, identificado en tres años y seis meses (véase Ap 11, 2-11; 13,4-10). La segunda razón se refiere al descenso del cielo nuevo y de la tierra nueva que hacen desaparecer aquello que todavía seguía existiendo. Se entiende que esto ocurre después de la segunda resurrección, mientras que la primera resurrección hace referencia a un acontecimiento que ha de producirse en el tiempo presente. 
Todas las generaciones, de Adán hasta el día de hoy, han pasado; mas los que fueron perfectos en la caridad, según la gracia de Dios, ocupan el lugar de los piadosos, los cuales se manifestarán en la visita del reino de Cristo. Está escrito, en efecto: Entrad un poco en vuestras recámaras, tanto cuanto, hasta que pase mi ira $y$ furor, y me acordaré del día bueno y os resucitaré de vuestros sepulcro ${ }^{2}$.

Se puede fácilmente apreciar que la referencia no es del todo clara en cuanto no se especifica un reinado intrahistórico de los justos, sino que los justos se manifestarán en la visita del Reino de Cristo, sin especificar si este reino será sucesivo al juicio final o anterior. Se puede intuir que Clemente se refiere a un reinado pero su descripción es demasiado escasa para poder avanzar hipótesis fundamentadas.

Otro texto a examinar es la Didaché, considerado el más antiguo escrito cristiano. Aquí también las referencias son demasiados escuetas para poder sacar conclusiones acertadas. Se distingue la primera y la segunda resurrección; después de la primera resurrección, el mundo seguirá existiendo y verá la gloria del Señor descender del cielo. He aquí el texto en cuestión:

Porque en los últimos días se multiplicarán los falsos profetas y corruptores [...] entonces la creación de los hombres vendrá al abrasamiento de la prueba y muchos se escandalizarán y perecerán. Mas los que permanecieren en su fe se salvarán por el mismo que fue maldecido. Y entonces aparecerán los signos de la verdad. Primeramente, el signo de la apertura del cielo; luego, el signo de la voz de la trompeta; y, en tercer lugar, la resurrección de los muertos. No de todos, sin embargo, sino como se dijo: Vendrá el Señor y todos los santos con él. Entonces verá el mundo al Señor que viene encima de las nubes del cielo ${ }^{3}$.

Si en la Didaché las referencias a la plenitud intrahistórica se reducen a una posible interpretación de las dos resurrecciones, en el Pastor de Hermas las referencias son, si cabe, aún más crípticas. Una posible referencia útil a nuestro estudio se encuentra en la comparación del presente siglo y el siglo venidero a través de la metáfora de los árboles secos y los árboles verdes. Los árboles secos representan los habitantes de este siglo, en el invierno, ya que no se pueden distinguir los justos de los pecadores. Pero en el siglo venidero, algunos están secos y otros verdes. Esto coincide con la manifestación de aquello que en el siglo pasado quedaba escondido, es decir, la diferencia entre los justos y los inicuos. En la revelación se explica que los árboles verdes "representan a los

2 Clemente de Roma, Carta primera a los corintios, 50, 3-4. En D. Ruiz Bueno, Padres Apostólicos y apologistas griegos, p. 205.

3 Didaché, 16, 3-8. En D. Ruiz Bueno, Padres, p. 93. 
justos que han de habitar en el siglo venidero, pues el siglo venidero es verano para los justos; más para los pecadores invierno"4. La cuestión de la manifestación de quién es cada hombre y lo que está escondido en su corazón, nos podría hacer pensar en el juicio final que inicia una época de plenitud con los justos; pero la doctrina explícita en la obra nos impide avanzar cualquier hipótesis y en particular si este posible reinado pertenezca a este siglo presente o trascienda esta realidad presente.

En cambio, el texto donde más resalta el esquema milenarista es la Carta de Bernabé. Aquí se presenta un esquema clásico del sábado vinculado con los días de la creación, para finalmente afirmar que una vez el mundo haya cumplido los seis mil años serán consumadas todas las cosas. En el día séptimo se preanuncia que:

Cuando venga su hijo y destruya el siglo del inicuo y juzgue a los impíos y mudare el sol, la luna y las estrellas, entonces descansará de verdad en el día séptimo [...] entonces por nuestro descanso lo santificaremos de verdad, cuando, justificados nosotros mismos y en posesión ya de la promesa, seremos capaces de santificarlo; es decir, cuando ya no exista la iniquidad, sino que nos hayamos vuelto todos nuevos por el Señor, entonces, sí, santificados primero nosotros, podremos santificar el día séptimo 5 .

En el pasaje en cuestión resulta de gran importación el uso el uso del esquema de los ocho días de la creación que unos siglos más tarde servirá a San Agustín para justificar su postura inicialmente milenarista. Según la Carta a Bernabé el séptimo día es una etapa donde el mal será finalmente vencido y que queda en medio de la edad presente y la edad del descanso eterno. No se especifica claramente si es una etapa intrahistórica ni si esta ocurrirá en este saeculum pues la intenciónd el autor podría entremezclarse a la cuestión de la superación de la observancia sabática. Lo que es cierto es que en el septimo día no habrá maldad y que será un descanso de los justos. Sin embargo, podemos encontrar un indicio de su intrahistoricidad en el recurso al octavo día que debe diferenciarse necesariamente del séptimo, ya que el octavo representa la vida eterna. En este sentido la Carta afirma que la acción de Dios se mueve en este sentido: "no me son aceptos vuestros sábados de ahora, sino el que yo he hecho, aquel en que, haciendo descansar todas las cosas, haré el principio de un día octavo, es decir, el principio de otro mundo" 6 .

\footnotetext{
4 El "Pastor" de Hermas, 3. En D. Ruiz Bueno, Padres, p. 785.

5 Carta de Bernabé, 15.4-6. En D. Ruiz Bueno, Padres, p. 610.

6 Ibidem, 15.8 .
} 
Pero tampoco este indicio es suficiente para poder probar sin lugar a dudas la subsistencia de este descanso en el tiempo presente. De hecho, señala Daniélou que la referencia al octavo día sería un helenismo y por ende la referencia a la semana bíblica no implicaría un milenarismo ni una esperanza intrahistóri$\mathrm{ca}^{7}$. De todos modos, nos parece forzado tener que recurrir a la explicación helenista para desestimar una posibilidad de esperanza intrahistórica. Solamente puede sostenerse esta posición a un precio muy alto, es decir, deshaciéndose de una larga tradición bíblica ${ }^{8}$.

Por último, merecen una mención Los tres libros a Autólico, atribuidos a Teófilo de Antioquia, obispo de la misma ciudad, que la tradición recuerda como el sexto sucesor de los apóstoles. En este texto, se hace un cálculo acerca de las edades del mundo y se fija implícitamente el nacimiento de Cristo hacia el año $5500^{9}$. De aquí se deduce que en el séptimo milenio que comienza en el año 6000 dará lugar al reino mesiánico, para finalmente acabar en el año 7000 con el fin del mundo y el comienzo de la ciudad celeste. Según Daniélou, el autor de este texto ha tenido con su esquema y cálculos una notable influencia sobre Ireneo y es considerado como uno de los primeros cristianos interesado en Teología de la historia ${ }^{10}$.

\section{Desviaciones y ortodoxia en la escuela asiática}

Varios autores han señalado la importancia de los elementos de la apocalíptica judía en autores cristianos como Cerinto y Papías en el primer siglo. Tanto es así que se ha llegado a considerar la influencia del ambiente judío sobre la existencia de un reino carnal intrahistórico como más predominante que

7 Cf. J. Daniélou, Teología del judeocristianismo, pp. 397-398.

8 El Antiguo Testamento rebosa de textos que preanuncian el reino futuro como reino de paz y justicia. Los salmos, los profetas Isaías, Amós y Joel contienen elementos que evocan la instauración próxima de un reino que cumplirá las promesas divinas de liberación de los oprimidos. Acerca de la persistencia, tanto en el Antiguo Testamento como en la historia de la teología, de la consumación intrahistórica del milenio, véase. J. Pueyo, La plenitud terrena del Reino de Dios en la historia de la teología. En los Apócrifos del Antiguo Testamento las esperanzas de redención se cargan de abundancias materiales. Cf. A. Diez Macho, Apócrifos del Antiguo Testamento, I, pp. 354-389. Acerca de la continuidad de esta idea hasta la Edad media y en particular en Santo Tomás, cf. P. Roszak, La fe y la participación en la naturaleza divina según santo Tomás de Aquino, pp. 153-172.

9 Cf. J. Daniélou, Teología del judeocristianismo, 401. Cf. Teófilo de Antioquía, Los tres libros a Autólico 3.28. En D. Ruiz Bueno, Padres, 1497.

10 Cf. J. Daniélou, Teología del judeocristianisimo, 400. 
los elementos presentes en el Apocalipsis de Juan para explicar la presencia de elementos materialistas en el interior de la comúnmente llamada "escuela asiática"11.

La doctrina de Cerinto es considerada por Ireneo de Lyon semejante a las de los ebionitas, los judaizantes que continuaban con las costrumbres y rituales judios al mismo tiempo que consideraban a Cristo como un mero hombre que se había hecho Dios ${ }^{12}$. Su visión del milenio era de tipo marcadamente material según el testimonio de Eusebio de Cesarea que lo describe centrado en "hartazgos del vientre y de lo que está debajo del vientre, es decir: en comidas, en bebidas, en uniones carnales"13. Según Simonetti, tanto la doctrina de Cerinto como la de Papías deben situarse en el ambiente asiático del primer siglo, que correspondería al mismo tiempo en que San Juan redactó el Apocalipsis ${ }^{14}$. Sabemos por Eusebio de Cesarea que Cerinto hablaba de un "número de mil años de fiesta nupcial" 15 de tipo enteramente material y volcado a satisfacer los placeres carnales. En este sentido podemos considerar las especulaciones de Cerinto ajenas a la ortodoxía ecclesial y fuera de la tradición.

En cambio, Papías fue el más antiguo Padre de la Iglesia que apoyó el milenarismo. Siendo obispo de Hierápolis entre el primero y el segundo siglo fue contemporáneo de Policarpo. De su obra Explicación de sentencias del Señor nos quedan unos fragmentos citados por Eusebio e Ireneo. Eusebio escribe que Papías no ha sido oyente de los apóstoles sino que refiere tradiciones de personas familiares a los mismos apóstoles ${ }^{16}$ y se dedicaba a discernir los discursos de ancianos que solían contar "qué dijo Andrés, o Pedro, o Felipe, o Tomás, o Santiago, o Juan, o Mateo o cualquier otro de los discípulos del Señor"17. A este propósito, Eusebio utiliza esta información para dar crédito a la existencia de dos hombres llamados Juan; uno, el autor del Evangelio; el otro, distinto del apóstol, autor del Apocalipsis. Esta información ha sido utilizada por varios estudiosos ${ }^{18}$ para sostener el intento tendencioso de Eusebio de desacreditar el Apocalip-

11 Cf. M. Simonetti. L'Apocalissi e l’origine del millennio, pp. 337-350. Cf. C. Mazzucco, E. Pietrella, Il rapporto tra la concezione del millennio dei primi autori cristiani e l'Apocalisse di Giovanni, pp. 29-45.

12 Cf. Ireneo de Lyon, Contro le eresie e gli altri scritti, 5,1.3, pp. 412-413.

13 Eusebio de Cesárea, Historia Ecclesiastica, 3.28.5, pp. 170-171.

14 M. Simonetti, L’Apocalissi, pp. 338-339. Cf. J. Daniélou, Teología del judeocristianismo, p. 384.

15 Eusebio de Cesárea, Historia Ecclesiastica, 3.28.2, p. 170.

16 Ibidem, 3.39.2, p. 190.

17 Ibidem, 3.39.4, p. 191.

18 Cf. C. Mazzucco, E. Pietrella, Il rapporto, pp. 32-33. 
sis, ya que — siendo Papías discípulo del segundo Juan, el milenarista autor del Apocalipsis - éste merece su menosprecio al punto de llamarlo "hombre de muy escasa inteligencia"19. De todas formas, acerca del milenarismo de Papías, Eusebio escribe estas palabras:

Entre ellas [extrañas parábolas] dice que, después de la resurrección de entre los muertos, habrá un milenio, y que el reino de Cristo se establecerá corporalmente sobre esta tierra. Yo creo que Papías supone todo esto por haber tergiversado las explicaciones de los apóstoles, no percatándose de que éstos lo habían dicho figuradamente y de modo simbólico ${ }^{20}$.

Señala Daniélou que este texto de Papías coincide con el de la Ascensión de Isaías que en su opinión sería la representación más primitiva del milenio en ámbito judeocristiano ${ }^{21}$. Podemos concluir que el testimonio de Eusebio acerca de Papías se ve influenciado por su antimilenarismo acompañado por un rechazo del Apocalipsis que, como mínimo, crea dudas acerca de su veracidad ya que parece haber distorsionado unas informaciones elementales para negar la validez de esta doctrina.

En cambio, Ireneo nos ofrece un relato más coherente de las ideas de Papías acerca del milenio esperado. En este caso, a Papías se le considera "oyente de Juan y compañero además de Policarpo"22, es decir, que había escuchado directamente la primera y la segunda predicación apostólica. A continuación siguen las palabras de Ireneo acerca de la doctrina de Papías:

La bendición susodicha se refiere, por tanto, fuera de duda, a los tiempos del reino: cuando, redivivos de entre los muertos, gobiernen los justos; y la creación, renovada y hecha libre, fructifique en abundancia toda suerte de manjares, del rocío del cielo y de la grosura de la tierra. Los Presbíteros, que vieron a Juan el discípulo del Señor, recuerdan haberle oído cómo, obre los tiempos aquellos, enseñaba el Señor y decía: "Días vendrán, en que nacerán viñas: cada una con diez mil cepas, y cada cepa con diez mil sarmientos, y cada sarmiento con diez mil racimos, y cada racimo con diez mil granos, y cada grano dará veinticinco metretas de vino. Y al ir alguno de los santos a coger un racimo, otro racimo clamará: Mejor soy yo, tómame a mí, bendice por mí al Señor. Parecidamente, el grano de trigo producirá diez

19 Eusebio de Cesárea, Historia Ecclesiastica, 3.39.13, p. 193. Aun sin llegar nunca a negar la autoría del Apocalipsis, Eusebio es deudor de Dionisio de Alejandría y de Origenes acerca de la interpretación alegórica del Apocalipsis.

20 Eusebio de Cesárea, Historia Ecclesiastica, 3.39.13, p. 193.

21 J. Daniélou, Teología del judeocristianisimo, p. 381.

22 Ireneo de Lyon, Contro le eresie e gli altri scritti, 5.33.4, p. 475. 
mil espigas, y cada espiga tendrá diez mil granos, y cada grano cinco bilibras de pura harina. Los restantes frutos y semillas y yerba irán en consonancia con esto. Y los animales todos, por servirse de los alimentos tomados de la tierra, se volverán pacíficos y conformes unos a otros, sujetos en todo a los hombres"23.

En el mismo relato de Ireneo, frente al estupor de semejante renovación del mundo, Jesús respondió al escéptico Judas que dudaba de su realización: "ya lo verán los que lleguen a aquello"24. Que la pregunta incrédula sea puesta en la boca de Judas, el mismo que no creyó en la promesa eucarística ${ }^{25}$, no es una casualidad; de hecho "estas cosas son creíbles a los que tienen fe" y Judas "no creía" 26 y por esto dudaba.

El testimonio de Papías cobra en Ireneo un valor mucho mayor que el otorgado por Eusebio. Papías no es el único autor y testigo de aquella narración extraordinaria, sino que fue tomada directamente y es avalada también por los "presbíteros" ${ }^{27}$ que oyeron las mismas palabras. Es entonces un testimonio digno de fe e Ireneo se hace portavoz e intérprete. Las promesas son de tipo material, pero no llegan a ser de orden carnal, en el sentido de que no se proponen comidas inmoderadas ni desviaciones morales. El tema recurrente es la fecundidad de la tierra puesta a disposición de los santos en el reino que les espera. Señala Orbe que "todos los frutos querrán servir a porfía al hombre para honrar, instrumentos de la gratitud, al Creador. Es el desquite de las criaturas, sujetas antes a la maldición" 28 . Además, el acento sobre la abundancia de las uvas, materia prima del vino, que se dirigen a los santos para que con ellas se bendiga al Señor, se vincula con la Eucaristía, que viene a significar, según Orbe: “Tómame a mí y haz de mí Eucaristía"29, es decir, tomar y dar gracias o bendecir. Esto refuerza la hipótesis según la cual la extraordinaria fecundidad de la tierra, finalmente librada de su maldición, se configura como un signo mesiánico no propiamente de tipo carnal, sino más bien dirigido a realidades espirituales. De hecho, la misma abundancia de vino se acompaña a la extraordinaria producción de espigas y harina, materias necesarias para el pan eucarístico.

23 Ibidem, 5.33.3-4, pp. 474-475.

24 Ibidem, 5.33.4, p. 475.

25 Cf. Jn 6, 60-64. También Hipolito señala la incredulidad de Judas. Cf. A. Orbe, Teología de San Ireneo, 3, p. 432.

26 A. Orbe, Teología de San Ireneo, p. 431.

27 Ibidem, p. 417.

28 Ibidem, p. 423.

29 Cf. ibidem, p. 422. 
La fecundidad espontánea de la tierra se relaciona con otro signo mesiánico que ya aparece en Isaías ${ }^{30}$, es decir, la reconciliación del mundo animal con los hombres y entre ellos, causado por la nutrición de los animales de alimentos vegetales. Este rasgo también puede ser incluido en la renovación de la creación que sigue al reinado de los justos. La particularidad de la doctrina de Papías es, a los ojos de Daniélou, aplicar "las descripciones del paraíso al reino terreno del Mesías" ya que refiere "al reino mesiánico profecías del Antiguo Testamento que se refieren al mundo futuro" 31 , lo que es típico de la escuela milenarista asiática. Ahora bien, estos elementos de fecundidad de la tierra parecen pertenecer no tanto a una exégesis del Apocalipsis sino a lo característico de la nueva creación. De hecho en el Apocalipsis de Juan no aparece esta abundancia material. A este propósito, parecen coincidir Daniélou, Simonetti y Mazzucco-Pietrella ${ }^{32}$, y también nosotros coincidimos. Su origen debería ser buscado en la tradicional doctrina judaica acerca del futuro reino mesiánico, donde aparecen elementos de tipo materialista.

De todas formas, se debe subrayar una vez más que los elementos materialistas de la doctrina de Papías no decaen en un materialismo craso de tipo heterodoxo, sino que manifiestan la renovación del mundo natural por parte de Dios y que viene puesto al servicio de los justos en el reino. De hecho, señala justamente Orbe, en esta renovación de la naturaleza, también los cuerpos de los santos experimentarán en este reino una primera trasformación a la espera del cuerpo glorioso final:

Los hijos de Dios recobrarán el misterioso esplendor o gloria que un tiempo tuvieron en Adán. Dueños, al menos, de sus pasiones; y en comunión pujante de espíritu con Dios, lograrán en sí propios "la unidad de espíritu" que les levanta en carne a ignoradas alturas ${ }^{33}$.

30 Cf. Is 65, 25. Sobre la fecundidad de la tierra, véase Am 9, 14. También hay rasgos comunes con la apocalíptica judía especialmente en el "Primer libro de Henoc" y en los “Oraculos Sibilinos". Cf. A. Diez Macho, Apócrifos del Antiguo Testamento, 4, 48; 6, 497-503.

31 Cf. J. Daniélou, Teología del judeocristianisimo, p. 383.

32 Cf. ibidem, p. 383. Cf. M. Simonetti, L’Apocalissi, pp. 339-340; C. Mazzucco, E. Pietrella, Il rapporto, p. 35. "Il collegamento instaurato indirettamente tra un millenarismo di questo genere e l'Apocalisse non si giustifica a partire da un'analisi del testo dell'Apocalisse, in cui gli elementi materialistici sono assenti dalla descrizione del regno e in cui si notano accenni ad un'interpretazione spirituale dei detti biblici e dei simboli usati”.

33 Cf. A. Orbe, Teología de San Ireneo, p. 416. 
Entonces, se puede concluir que, según Papías, la fecundidad de la tierra no está ordenada a un desenfreno carnal sino a una manifestación de la redención de la naturaleza en vista de un mayor provecho espiritual de los justos.

\section{Desarrollos del milenarismo de la escuela asiática: Justino, Ireneo e Hipólito}

Si en Papías la raíz del milenarismo debería ser encontrada en la apocalíptica judía, en Justino se produce la conexión entre el Apocalipsis de Juan y la creencia de que en los mil años la Jerusalén terrena será reedificada como la capital del milenio. Se ha notado que este aspecto terrenal de la Jerusalén celestial en el Apocalipsis se había logrado superar a través de la separación entre el reino milenario y el descenso de la nueva Jerusalén a través de la última batalla de Satanás con la duración de tres años y seis meses, cuestión que Justino omite. En el Dialogo con Trifón encontramos explícitamente afirmada la reconstrucción de Jerusalén en el milenio; posición que también Cerinto anteriormente había defendido ${ }^{34}$. Después de haber citado la profecía de Isaías sobre el "cielo nuevo y tierra nueva" donde Dios se "regocijará en Jerusalén" en la cual no habrá "voz de llanto ni voz de grito" y donde "pacerán juntos el lobo y el cordero" (Is 65, 17-25), Justino afirma frente al judío Trifón:

Lo que en estas palabras, pues, se dice —dije yo—: "Porque según los días del árbol de la vida, serán los días de mi pueblo, envejecerán las obras de sus trabajos”, entendemos que significa misteriosamente los mil años. Porque como se dijo a Adán que el día que comiera del árbol de la vida moriría, sabemos que no cumplió los mil años. Entendemos también que hace también a nuestro propósito aquello de "Un día del Señor es como mil años". Además, hubo entre nosotros un varón por nombre Juan, uno de los Apóstoles de Cristo, el cual, en revelación que le fue hecha, profetizó que los que hubieren creído en nuestro Cristo, pasarán mil años en Jerusalén (Ap 20,4-6); y que después de esto vendría la resurrección y juicio de todos unánimemente ${ }^{35}$.

Según Justino, en el milenio se producirá la restauración de la Jerusalén terrenal. Esta interpretación encuentra en el Apocalipsis de Juan una mayor justificación, ya que se vincula con la historia de Adán en el Génesis y las profecías de Isaías. De hecho, destaca Daniélou, en toda la tradición asiática del milenarismo, de la cual Justino es portavoz, el reino mesiánico es un regreso

35 Justino, Dialogo con Trifón, 81.3-4. En D. Ruiz Bueno, Padres, p. 1198. 
al paraíso perdido y por esto resulta "normal que la duración de la vida en éste sea la que hubiese debido tener la vida de Adán" ${ }^{36}$. Entonces, los elementos que confluyen en Justino, son los típicos que suelen atribuirse al milenarismo de escuela asiática: la "Jerusalén renovada, la reconciliación de los animales, la longevidad [...] El único elemento que no aparece explícitamente es el logion sobre la fecundidad de la viña" ${ }^{37}$, que hemos descrito en Papías. La longevidad de los justos en el milenio es confirmada, además de por la referencia a la vida de Adán, también a través de la continuación del texto citado anteriormente: "lo mismo vino a decir también nuestro Señor: no se casarán ni serán dadas en matrimonio, sino que serán semejantes a los ángeles, hijos que son del Dios de la resurrección" ${ }^{38}$. Se puede decir que los justos después de la primera resurrección, gozarán de una tierra renovada en una vida terrena, a la espera de gozar la plenitud de Dios después del juicio final. Trasladando el milenio de Adán al reino de los justos y relacionándolo finalmente con el pasaje evangélico que excluía el matrimonio en la vida futura, se deduce necesariamente que los justos reinarán el tiempo de una generación de la duración de mil años, tiempo en el cual no se contempla la generación de vida humana. Según Justino, después de la primera resurrección, el reino de los justos será la restauración del estado paradisíaco, al cual se le aplican las categorías de la vida adámica del Génesis, las profecías mesiánicas de Isaías y elementos de la apocalíptica judía, excluyendo la fecundidad de la tierra y de los hombres ${ }^{39}$.

Frente al desafío del intelocutor judío de Trifón, este se ve obligado a confesar que espera la reconstrucción de la ciudad de Jerusalén, la reunión del pueblo elegido con Cristo. La respuesta de Justino es lapidaria: "no soy tan miserable de decir una cosa y sentir otra" ${ }^{40}$. Esta acusación le ofrece la posibilidad de aclarar que para él y otros muchos cristianos estas cosas deben realizarse pero que al mismo tiempo hay cristianos rectos que no admiten estas ideas. En la exposición de Justino se omite la referencia a la ofensiva final de Satanás contra los santos presente en el Apocalipsis. Como bien señalan Mazzucco y Pietrella, el milenarismo de Justino parece ser más deudor de la apocalíptica judaica que del Apocalipsis de Juan, y se inserta en el milenarismo moderado de la escuela asiática. Nos parece que el milenarismo de Justino es parte integrante de su doctrina y la reacción desdeñosa frente a las acusaciones de falsedad por parte de Trifón testimonia la importancia que Justino otorgaba a la cuestión escatológica a pe-

\footnotetext{
36 Cf. J. Daniélou, Teologia del judeocristianismo, p. 392.

37 Ibidem.

38 Justino, Dialogo con Trifón, 81.3-4, p. 1198.

39 Cf. J. Daniélou, Teología del judeocristianismo, p. 394.

40 Justino, Dialogo con Trifón, 80.1, p. 1196.
} 
sar de las incongruencias que se producían entre la tradición de la apocalíptica judía, las profecías veterotestamentarias y los elementos del milenio presentados por Juan ${ }^{41}$.

Por lo que concierne a Ireneo de Lyon, se puede adscribir a la escuela asiática sin que pueda reducirse su doctrina milenarista a un mero añadido a su edificio teologico. Después de citar a las profecias de Isaías en las cuales se afirma la llegada del día furente del Señor (Is 13, 29), Ireneo sigue al profeta también para justificar el reinado de los santos en el milenio:

Ocurrido esto, dice (Is 6, 12), alargará Dios los días de los hombres, y los remanentes se multiplicarán en la tierra (Is 65, 21): y construirán casas y ellos las habitarán; y plantarán viñas y ellos las gustarán. Todo esto se dijo indudablemente con miras a la resurrección de los justos, que viene después del advenimiento del Anticristo y perdición de todas las naciones a él sujetas. Reinarán a la sazón los justos en la tierra, creciendo a vista del Señor, y por su medio se harán a aprehender la gloria de Dios Padre, y junto con los santos ángeles captarán en el reino el régimen y comunión y unidad de los espirituales. Por cuanto hace a los que el Señor hallará en vida, aguardando su venida de los cielos, y con experiencia de la tribulación - los mismos que escaparon al poder del inicuo- dice de ellos el profeta (Is 6, 12): "Y los remanentes se multiplicarán en la tierra". En cambio, a cuantos de entre las naciones dispuso Dios a fin de multiplicar en la tierra a los remanentes y someterse al reino de los santos y servir a Jerusalén, y ser reino en ella, los significó así el profeta Jeremías $[\ldots]^{\prime \prime 2}$.

Después de haber barrido el mundo de los impíos, el reinado de los santos podrá instaurarse. Ireneo identifica tres tipologías de santos ${ }^{43}$ que reinarán en Jerusalén: los primeros son los justos que ya murieron y resucitan en la primera resurrección y se presentan como los más dignos habitantes del reino; los segundos son los derelicti, aquellos israelitas que escaparon de morir por mano del Anticristo y sobrevivieron; por últimos, los justos dispersos por el mundo, no israelitas, que no se dejaron vencer por el pecado durante la persecución. Los primeros, los redivivos, reinarán en la tierra, no se multiplicarán en hijos y serán hasta superiores a los ángeles. Ellos se habituarán progresivamente (crescentes) en cuerpo y alma a la visión de Dios Padre y reinarán sobre la Jerusalén terrena; los otros dos grupos estarán gobernados por los justos y los servirán. Si los

41 Cf. C. Mazzucco, E. Pietrella, Il rapporto, p. 41.

42 Ireneo de Lyon, Contro le eresie e gli altri scritti 5.35.1, p. 478.

43 Cf. A. Orbe, Teología de San Ireneo, pp. 496-497; cf. idem, Introducción a la teología de los siglos II y III, pp. 966-967. 
primeros crecen en la visión beatifica, los otros se multiplicarán en hijos sobre la tierra ${ }^{44}$.

El segundo grupo, los derelicti, es decir, los remanentes de Israel, crecerá y se multiplicará en la tierra a través del matrimonio. Estos serán perseguidos ferozmente por el Anticristo y en la misma carne en la cual sufrieron la persecución, participarán de la gloria del Señor. En el nuevo reino, ellos construirán casas, las habitarán y cultivarán; a diferencia del primer grupo, no poseen la vida angélica que les exime de las necesidades materiales.

El tercer grupo, ex gentibus, se identifica con los creyentes venidos del paganismo. Han sido preparados por Dios para multiplicarse con los justos procedentes de Israel, para que también los paganos puedan participar por comunión con los israelitas en el milenio, y por último para servir al reinado de Jerusalén. Afirma Orbe que "los santos reinarán a una con Cristo. Los derelicti serán como sacerdotes; los praeparati como levitas o diáconos, al servicio de los primeros" 45 .

Ahora bien, de las palabras de Jesús acerca de volver a beber el fruto de la vid junto con sus discípulos, Ireneo afirma que esto "es cosa de la carne, y no del espíritu, la bebida que se saca de la vid" 46 . En este aspecto no perdura la diferenciación de los tres grupos de habitantes del reinado: el pan y el vino eucarísticos serán el alimento y la bebida que acomunará a todos los que confluirán en el milenio. Los redivivos del primer grupo, a pesar de no tener necesidad de comer, podrán hacerlo para comer el manjar eucarístico, conduciendo, como hemos dicho, un régimen de vida completamente espiritualizado en la carne.

Podemos afirmar que los tres grupos habitantes del milenio vivirán en la carne, por cierto, diferentemente espiritualizada y no habrá pecado o desviaciones morales. El grupo de los israelitas tendrá una ventaja a causa de su estirpe sobre los gentiles y ambos se someterán a las órdenes de los redivivos.

En referencia a Ap, 20, Ireneo se decanta por una interpretación literal del milenio y a diferencia de Justino, distingue el reino milenario de la nueva Jerusalén, introduciendo entre medio el juicio final. De este modo es posible la preparación de los santos a la nueva realidad de la Jerusalén celeste:

Dice Juan, el discípulo del Señor, que sobre la tierra nueva desciende la Jerusalén superior, como esposa engalanada para su marido; y es éste el tabernáculo de Dios, en que habitará Dios con los hombres. Imagen de esta Jerusalén era la Jerusalén de

44 Cf. idem, Teología de San Ireneo, pp. 501-502. De los primeros es caracteristica la perfecta adhesión al Espíritu (communio) y la semejanza con Dios (unitas).

45 Idem, Introducción, p. 976.

46 Ireneo de Lyon, Contro le eresie e gli altri scritti, 5.33.1, p. 473. 
la tierra precedente, en que los justos se disponían a la incorruptela y preparaban a la Salud ${ }^{47}$.

Los elementos de fertilidad de la tierra en el reino futuro se hacen remontar a la bendición de Isaac a su hijo menor Jacob por una predicación no escrita del Apóstol Juan y al testimonio de Papías citado anteriormente.

En definitiva, el milenarismo de Ireneo utiliza una interpretación literal y no alegórica de los pasajes bíblicos; que hay grados de beatitud en el reino milenario donde Cristo reina; que la Jerusalén terrena será renovada y librada de toda impiedad y la vida del milenio que se desarrollará en ella servirá de preparación progresiva al descenso de la Jerusalén celestial.

Por último, no podemos dejar de mencionar a Hipolito ${ }^{48}$ que vivió entre el segundo y el tercer siglo, tenemos huellas en dos de sus escritos: El Anticristo y el Comentario a Daniel. En la segunda obra encontramos los cálculos que justifican la presencia del milenio, que alude a los seis mil años del mundo y que deberá producirse al entrar en el séptimo día de la historia, el Sábado del descanso:

Es necesario que hayan transcurrido los seis mil años para que llegue el Sabbat, el descanso, el día consagrado en el que el Señor descansa en todas sus obras [...] El Sabbat es el tipo y la figura del reino de los santos, en el que reinarán con Cristo, cuando venga de los cielos, como Juan expone en su Apocalipsis. En efecto, el día del Señor es como mil años. Puesto que el Señor ha hecho el universo en seis días, es preciso que se completen los seis mil años. Todavía no se han cumplido, según las palabras de Juan: los cinco primeros han caído, subsiste uno, el otro no ha llegado todavía $\left(\right.$ Ap 17, 10). Por "el otro" designa el séptimo, en el que se establecerá el descanso ${ }^{49}$.

En toda la exposición de Hipólito acerca de los misterios futuros encontramos una sobriedad típica de la escuela occidental, donde no aparecen signos extraordinarios acerca del reinado, sino simplemente el gozo de la victoria de Cristo y la derrota final del Anticristo.

Gracias al descubrimiento del manuscrito original de los Meteoros del Comentario a Daniel, se ha observado ${ }^{50}$ que la creencia en la doble resurrección

47 Ibidem, 5.35.2, p. 480.

48 Acerca de la controversia sobre el Hipolito e Hipolito de Roma, cf. A. Di Berardino, Nuovo dizionario patristico e di antichità cristiane, pp. 2584-2604.

49 Hipólito, Commentaire sur Daniel, pp. 307-309. Se ha visionado la traducción parcial de J. Daniélou, Teología del judeocristianismo, pp. 400-401.

50 Cf. A. Martínez Esteban, ¿Hipólito milenarista? A propósito de In Danielem IV, 56, 1-7. En E. De La Lama (dir.), Dos mil años de evangelización: los grandes ciclos evangelizadores, pp.195-209. 
fundamenta el milenarismo de Hipólito. La nueva lectura del texto en cuestión encontraría apoyo también en un pasaje de El Anticristo ${ }^{51}$ que confirmaría los paralelismos de los textos y su coherencia. Finalmente, gracias a la adición del texto que introduce el Manuscrito de los Meteoros, debería leerse:

Unos [resucitarán] para resurrección de vida, en posesión de cuerpos puros, brillantes y resplandecientes; pero otros para una resurrección de juicio, con cuerpos sólo aptos para el castigo eterno. Como también dice Juan: "Bienaventurado y santo el que tiene parte en la resurrección primera" (Ap 20,6). [Adición del Manuscrito de los Meteoros]. Sobre éstos la segunda muerte no tiene poder" (Ap 20,6). Porque la muerte segunda es el estanque de fuego abrasador (Ap 20, 14) ${ }^{52}$.

De este modo, Hipólito afirma dos resurrecciones; la primera es la de los justos con la manifestación gloriosa de Cristo que dará vida al reinado milenario; la segunda es la resurrección para el juicio, en la cual los santos juzgarán con Cristo. Será un reinado de tipo espiritual, donde no habrá opresión o tentación, en definitiva no habrá más pecado y finalmente la creación se verá librada de la corrupción. Pasados los mil años y llevado a cabo el juicio final, los que gozaron de la primera resurrección entrarán en la eternidad de alabanza a Dios y plenitud infinita.

\section{Persistencia y negación del milenarismo en Occidente}

El milenarismo de la llamada escuela occidental surgió después de la escuela asiática. De los autores que pueden ser reconducidos en este apartado, nos limitaremos a Victorino de Petovio y Lactancio para finalmente centrarnos en las aportaciones de Jerónimo y Agustín. Como señala Daniélou, la diferencia sustancial entre las dos escuelas que estamos examinando es que la occidental difiere "de la concepción asiática en que (en relación al milenio) implica el cese de la acción creadora de Dios, mientras que la de los asiáticos implica su

51 Hipólito, El Anticristo, pp. 111-112. "Y el profeta dice: 'Ve despertando, tú que duermes, y despierta de la muerte, y te iluminará Cristo'. Y Juan dice: 'Bienaventurado y santo el que participa en la primera resurrección: sobre éstos la segunda muerte no tiene poder. Pues la segunda muerte es el lago de fuego encendido'. Y otra vez el Señor dice: 'Entonces los justos resplandecerán como el sol brilla en su gloria. Y les dirá a los santos: Venid aquí, benditos de mi Padre, heredad el reino preparado para vosotros desde que se echaron los cimientos del mundo".

52 A. Martínez Esteban, ¿Hipólito milenarista?, p. 200. 
intensificación" ${ }^{53}$. Esta diferencia se nota sobre todo en el tipo de milenio que se prefigura: en la escuela asiática hay tintes paradisíacos, como la fecundidad de la tierra, la reconciliación de los animales, la longevidad, mientras que en la escuela occidental el reino de los santos es más bien el descanso de los santos.

El primer autor occidental sobre el cual fijaremos nuestra atención es Victorino de Petovio. Su Comentario al Apocalipsis es el escrito más antiguo de este tipo que ha llegado hasta nosotros. Cuando Victorino escribe su Comentario, el milenarismo ya se presenta muy debilitado a causa de la cultura alejandrina, que a partir del tercer siglo se había difundido en el actual Oriente Medio y las regiones asiáticas. En aquel entonces el milenarismo asiático se resentía de los intentos de asimilación por parte del espiritualismo platónico. También por este influjo, su milenarismo tiene influencias origenistas y se presenta como alegórico y espiritual. A pesar de la influencia platónica, Jerónimo de Estridón por sus posiciones antimilenaristas modificó y escribió el Comentario de Victorino para quitar lo que en éste había de literal ${ }^{54}$. A los fines de nuestro estudio, resulta imprescindible comentar los pasajes relativos a los capítulos 20 y 21 de su obra.

Victorino distingue claramente dos resurrecciones. Al cabo de la primera tendrá lugar el reino milenario de los que están "escritos en el libro de la vida":

Nadie ignore que, para la venida del Señor, el diablo rojo y todos sus angeles apóstatas serán encerrados en la gehenna del infierno y soltados después de mil años a causa de las gentes que hayan servido al Anticristo, para que perezcan ellas solas, porque así lo han merecido; después tendrá lugar el juicio universal. Por eso dice: $Y$ revivieron los muertos inscritos en el libro de la vida y reinaron con Cristo durante mil años. Esta es la primera resurrección ${ }^{55}$.

Este reinado tendrá lugar en la Jerusalén terrenal, en la primera resurrección cuando "será mostrada la ciudad santa que ha de bajar del cielo" ${ }^{\text {; }}$; los detalles de la ciudad descritos en el Apocalipsis son entendidos de forma alegórica por Victorino, como por ejemplo la variedad de perlas preciosas que adornan la ciudad que significan la "preciosísima variedad de la fe de cada uno de los hombres" o cuando se refiere a las puertas hechas de perlas de la ciudad se quiere significar a los apóstoles ${ }^{57}$.

\footnotetext{
3 J. Daniélou, Teología del judeocristianismo, p. 402.

54 Cf. C. Curti, Il regno millenario in Vittorino di Petovio, pp. 419-433.

55 Victorino de Petovio, Comentario al Apocalipsis y otros escritos, p. 203.

56 Ibidem, p. 213.

57 Cf. ibidem, p. 229.
} 
Antes de instaurarse el reinado de los santos, deberán suceder tres cosas: la aparición del Anticristo, la predicación del Evangelio a todos los pueblos y la conversión de los judíos. El reinado del Anticristo y su persecución durarán tres años y seis meses y será precedido por la aparición de Elías y Jeremías que llamarán a los judíos a la fe cristiana ${ }^{58}$. Solamente después de la derrota del Anticristo será instaurado el reino milenario.

Acerca del reino, Victorino lo describe sin pomposidad, con caracteres más bien espirituales, que conviven con otros de tinte más material. Estos últimos bienes se orientan a Dios y a menudo son espiritualizados:

En este reino los que fueron desposeídos de sus bienes a causa del nombre del Señor, así como la multitud de los que fueron asesinados soportando toda clase de injusticia y cárceles -antes de la venida del Señor los santos profetas fueron lapidados, mutilados, asesinados- recibirán su consuelo, es decir, coronas y riquezas celestes. [...] En este reino será guardada toda la creación y, por mandato de Dios, sacará fuera los bienes escondidos en ella. Aquí recibirán los santos oro en vez de bronce y plata en vez de hierro, y piedras preciosas ${ }^{59}$.

La consolación es el bien prometido a aquellos que pacientemente han aguardado el retorno de su Señor y han escapado conservándose en la fidelidad de la persecución del Anticristo. Como bien señala Curti, Victorino se coloca entremedio de la cultura asiática y alejandrina, y se refleja en la sobria convivencia de elementos espirituales, como el consuelo y elementos materiales, que suelen explicarse a través de una exégesis alegórica ${ }^{60}$.

Otro autor digno de tomarse en consideración es Lactancio, que se muestra partidario de la instauración del reino milenario después de un tiempo de confusión causado por el Anticristo. Con algún elemento materialista, en el milenio de Lactancio se repiten rasgos que hemos comentado anteriormente por otros autores. En primer lugar la fertilidad de los habitantes: "durante estos mismos mil años engendrarán una multitud infinita y su descendencia será santa y querida por Dios" ${ }^{61}$. Después de cambios radicales en los seres naturales, esta fecundidad se traslada también a la tierra:

La tierra dará muestras de su fecundidad y producirá espontáneamente fertilísimos frutos; las rocas de los montes rezumarán miel, por los arroyos correrá el vino y los ríos inundarán con leche; el propio mundo, por fin gozará; toda la naturaleza se

Cf. ibidem, pp. 127-129; 149-161.

59

Ibidem, pp. 225-227.

60

Cf. C. Curti, Il regno millenario, pp. 432-433.

61 Lactancio, Instituciones divinas, 2, p. 340. 
alegrará al ser arrebatada y librada del dominio del mal, de la impiedad, del crimen y del error ${ }^{62}$.

Se puede notar cómo la extraordinaria fecundidad es fruto de la erradicación del mal en el milenio. Esto da lugar también a la pacificación del orden natural, primeramente en las bestias, tal y como profetizó Isaías:

Las bestias no se alimentarán de sangre en este tiempo, ni las aves de sus presas, sino que todo estará tranquilo y plácido. Los leones y los terneros estarán juntos en los mismos pesebres, los lobos no raptarán ovejas, los perros no cazarán, los gavilanes y águilas no dañarán, los niños jugarán con las serpientes ${ }^{63}$.

A pesar de la convivencia de elementos procedentes también de la cultura pagana, el milenarismo de Lactancio se configura como una síntesis de las dos escuelas. No faltan las referencias a la extraordinaria fecundidad de la tierra y de los hombres y de la pacificación del mundo animal; pero siempre se acompañan de la descripción de un reinado de adoración y alabanza a Dios que finalmente vive con los hombres en el milenio.

En el IV siglo la tendencia milenarista tanto en Occidente como en Oriente se había apagado con las aportaciones de Jerónimo de Estridón y Agustín de Hipona. El primero, en particular, es deudor de la visión origenista sobre el milenarismo que, según el autor alejandríno, era imputable a una interpretación superficial y literal de la Escritura ${ }^{64}$.

Jerónimo suele hacer coincidir los milenaristas con los judaizantes. Una idea de un reinado milenario en ámbito cristiano le resulta sumamente necia y absurda. Comentando el pasaje del Evangelio de Mateo en el cual se promete el céntuplo a los que dejaron todo para el seguimiento de Jesús, afirma:

Con ocasión de esta sentencia algunos interponen los mil años después de la Resurrección, diciéndonos que entonces se nos devolverá el céntuplo de todas las cosas que habíamos abandonado y también la vida eterna, no comprendiendo que, si en lo demás la promesa es adecuada, en cuanto a las esposas aparece la tontería de que quien ha abandonado una por causa de Señor recibirá ciento en el futuro. El sentido, por tanto, es éste: quien ha abandonado por causa del Salvador las cosas

62 Ibidem, p. 341.

63 Victorino de Petovio Comentario, p. 341.

64 Cf. Origenes, I principi, II, 11, 7, pp. 487-489. Sobre la interpretación del milenio de Origenes remitimos al estudio de H. Pietras, I prinicipi II, 11 di Origene e il millenarismo. En L. Perrone (dir.), Origeniana Octava, 1, pp. 707-714. 
carnales, recibirá cosas espirituales, las cuales en comparación y mérito suyo serán como si con un número pequeño se compara el número ciento ${ }^{65}$.

Jerónimo excluye a priori cualquier posibilidad de un reinado de mil años. Con respecto a la reconstrucción de Jerusalén afirma que "cuando esta ciudad haya sido destruida, nunca jamás será edificada, de forma que se interrumpan el reino de mil años y los sueños de la Jerusalén dorada y enjoyada"66. La comparación entre Sara y Agar le otorga la posibilidad de ridiculizar la creencia acerca de la fecundidad de los hombres en el milenio:

Tampoco la abundancia de bienes es lo que se debe esperar. En este sentido Jerónimo se aleja definitivamente de la escuela asiática:

El Señor, pues, promete al alma no, como dicen los quiliastas, abundancia de recursos, alimentos delicados, crasitud del cuerpo, faisanes, palomas rellenas, vino dulce, vino puro, belleza de las esposas y multitud de hijos, sino las delicias a que el Señor nos invita místicamente, al decir: Deléitate o con delicias disfruta en el Señor, $y$ te dará las peticiones de tu corazón ${ }^{67}$.

En su aversión hacia la interpretación carnal, Jerónimo no tiene reparo en incluir también a Ireneo, Padre de la Iglesia, poniéndolo a la misma altura de los quialistas. Antes de mostrar la correcta interpretación espiritualista de los pasajes bíblicos que atañen al milenio, afirma que no seguirá los "cuentos judíos" que esperan "que baje del cielo una Jerusalén de gemas y oro". Esto es "algo que también muchos de nosotros [...] prometemos" y entre estos "para citar a los autores griegos y unir el primero y al último, Ireneo y Apolinar"68. Consciente de esta injusta comparación, Jerónimo subraya un aspecto importante, es decir, que hay hombres ilustres en la Iglesia que han sostenido esta posición y que no se pueden condenar tan fácilmente. La referencia a Ireneo es implícita pero igualmente clara:

Aunque nosotros no sigamos dicha interpretación, no podemos, no obstante, rechazarla por haber sido ésta refrendada por muchos varones de la Iglesia y de

65 Jerónimo de Estridón, Comentario a Mateo, 2.12. En Obras completas, 2, p. 267.

66 Jerónimo de Estridón, Comentario a Isaías, 8.25.1-5. En Obras completas, 6a, p.597.

67 Ibidem, 15.55.3. En Obras completas, 6b, p. 201.

68 Jerónimo de Estridón, Comentario a Ezequiel, 11.36.1-15. En Obras completas, 5b, p. 181. 
los mártires; así que, que cada uno abunde en su sentido y remítase todo al juicio del Señor ${ }^{69}$.

Finalmente, Jerónimo trata de ofrecer una interpretación espiritual de los pasajes en cuestión, especialmente de Isaías y del Apocalipsis. En este sentido, Jerónimo no rechaza absolutamente el advenimiento de una época intrahistórica de plenitud, marcadamente de orden espiritual. Refiriéndose a Is, 60, afirma que la promesa de glorificar a Jerusalén debe entenderse referida enteramente a la Iglesia y a su consumación. La plenitud debe realizarse en el curso de la historia:

Y a tu luz caminarán las gentes. Todos nosotros caminaremos a la luz de los apóstoles, que luce en el mundo, mas las tinieblas no la apresaron, y los reyes, afirma, al resplandor de tu orto, tan pronto como naciste en Cristo. Esto se cumple espiritual y carnalmente, de forma que los reyes, cuyo corazón está en la mano del Señor y respecto a los que no reina el pecado en el cuerpo mortal, caminan al resplandor de la Iglesia naciente o al que ha salido en la Iglesia, y someten los cuellos a la fe del auténtico rey, Cristo. Vemos cotidianamente que esto se realiza cuando, suprimidos el error de la idolatría y la rabia de la persecución, los príncipes romanos pasan a la fe y tranquilidad de $\mathrm{Cristo}^{70}$.

Esta plenitud de la Iglesia que se debe realizar en el tiempo presente, en la cual los reyes temporales se someterán al único rey Cristo, se alcanzará con el extraordinario acontecimiento del pueblo judío. Por esta razón, Jerónimo no niega una plenitud intrahistórica y no condena a los que defienden esta postura, siempre y cuando se especifique que se realizará espiritualmente:

Hay quienes aguardan para el tiempo futuro, cuando todo Israel va a ser salvado una vez que haya entrado la totalidad de las gentes, todo esto que yo recuerdo cumplido en parte y por realizarse totalmente tras la primera llegada del Salvador hasta la consumación del mundo. La opinión de ésos no ha de reprobarse en modo alguno, mientras separemos que esto ha de cumplirse espiritual y no carnalmente ${ }^{71}$.

De este texto se entiende que Jerónimo se limita a negar las fantasías carnales de los milenaristas y judaizantes, sin excluir una época de plenitud de la Iglesia. Siguiendo esta línea, también los pasajes del Apocalipsis deben enten-

69 Jerónimo de Estridón, Comentario al profeta Jeremías, 4.9.10-11. En Obras completas, 7, p. 317.

70 Jerónimo de Estridón, Comentario a Isaías, 17.60.1-3, 6b, p. 331

71 Ibidem, 331-333. 
derse en sentido místico ${ }^{72}$ y no carnal. Esta interpretación que distancia Jerónimo de la literalidad de la escuela asiática, le permite igualmente afirmar un periodo indefinido de plenitud de la Iglesia entendida en sentido espiritual. En esta dirección, se deben entender estas palabras de Jerónimo, que se refieren $\mathrm{Za}$, 14, cuando se anuncia que el Señor será rey sobre toda la tierra, en verano y en primavera:

En cuanto a las palabras siguientes, y las habrá en verano y en invierno $[. .$.$] diremos$ que en aquel tiempo no hay invierno, sino una primavera y verano perpetuos, y se escuchará en nuestra tierra el arrullo de la tórtola, las higueras darán gruesos higos, florecerán las viñas, el invierno pasará y la lluvia se alejará y se irá. En aquel tiempo la primavera será inevitable porque las flores brotarán en nuestra tierra para que celebremos la Pascua y Pentecostés, días en que de lo terreno pasaremos a lo celestial y ofreceremos al Señor todos nuestros frutos. [...] Entonces el Señor será rey sobre toda la tierra y diremos: El Señor ha reinado; exulte la tierra, y también: Pregonad entre los pueblos que el Señor ha reinado. Pues ha enderezado el orbe de la tierra y ya no se moverá ${ }^{73}$.

Por lo que se ha comentado, Jerónimo es vehemente adversario de las interpretaciones carnales y de sus desviaciones, incluyendo la exégesis literaria de los pasajes bíblicos. Reconoce que la interpretación espiritual es la única adecuada para acercarse a los textos proféticos, y que a través de esta exégesis se admite un periodo intrahistórico de plenitud referido a la Iglesia, donde la tierra se llenará de delicias espirituales y también los reyes mundanos reconocerán a Cristo como único y soberano Rey.

Por último, la interpretación del milenio de Agustín de Hipona es diametralmente opuesta entre el contenido de los Sermones y el de Ciudad de Dios. Para Agustín la cuestión escatologíca es de vital a tal punto que "quien no piensa en el siglo futuro, y no se hizo cristiano esperando recibir al fin lo que Dios prometió, todavía no es cristiano"74. A lo largo de los Sermones aparecen claras referencias al apoyo de Agustín a la doctrina milenarista:

72 Cf. Jerónimo de Estridón, Comentario a Ezequiel, 11.38.1-23, 5b, p. 219. “[...] todo este libro de Juan, que lleva el subtítulo de Revelación, es una obra mística, y que necesitamos la revelación para poder decir con el profeta: Abre mis ojos para que contemple las maravillas de tu ley".

73 Jerónimo de Estridón, Comentario a los profetas menores, 11.38.1-23. En Obras completas, 3b, p.703.

74 Agustín de Hipona, Sermones, 9.4. En Obras completas, 7, p. 150. 
Como dice la Escritura, Dios reinará con sus santos en la tierra, y tendrá aquí una Iglesia de la que no formará parte malo alguno, aislada y purificada de todo contagio de maldad. [...] La Iglesia aparecerá aquí, ante todo, envuelta en gran resplandor, honor y justicia. No será posible allí el engaño, la mentira ni el que un lobo se oculte bajo la piel de oveja. Pues, como está escrito, vendrá el Señor, e iluminará lo oculto de las tinieblas y manifestará los pensamientos del corazón, y entonces cada uno recibirá la alabanza de parte de Dios. Allí no estarán, pues, los malvados; ya habrán sido separados ${ }^{75}$.

En este sentido, el juicio final se considera una etapa más en la historia del mundo, donde la Iglesia será preservada de todo mal. Este suceso deberá ocurrir en este tiempo presente que es donde se ha desarrollado la historia de la humanidad. El juicio deberá producir sus frutos en el tiempo que es juzgado:

Como al trigo, se lo limpia en el mismo lugar en que ha sido trillado, y el lugar en que los granos sufrieron la trilla para ser separados de la paja se embellece con la hermosura del muelo ya limpio. [...]. De la misma manera, después de la aventación del día del juicio aparecerá el muelo de los santos, resplandeciente por su dignidad, poderoso en méritos, teniendo ante sus ojos la misericordia de su liberador. Tal será el séptimo día ${ }^{76}$.

Alejándose de las expreciones que podían sonar aunque remotamente a milenaristas (por esto no se usa la expresión "mil años”) Agustín prefigura un tiempo futuro intrahistórico en el mismo lugar de consumación del juício pues así podrá resplandecer más clararamente la misericordia de Dios y los méritos de los santos. Su posición milenarista es confirmada también en la división de la historia del mundo en ocho días. El tiempo presente sería el actual, mientras que entre la septima y la octava edad la gran diferencia es la temporalidad de una y la eternidad de la otra pues en la octava se produce la resurreción de los cuerpos, mientras que en la septima se produce el descanso de los santos en la tierra cuya puerta de acceso son las obras de misericordia.

El cambio de perspectiva queda patente en su interpración contenida en el De civitate Dei, cuando después de describir la opinión de los que han creido en un milenio intrahistórico afirma:

Esta opinión sería hasta cierto punto admisible, si se creyera que durante ese sábado los santos gozarán de algunas delicias por la presencia del Señor. Yo mismo me he adherido algún tiempo a ese sentir. Pero sus defensores dicen que los resucitados

75 Agustín de Hipona, Sermones 259.2. En Obras completas, 24, p. 605.

76 Ibidem, pp. 605-606. 
se holgarán en inmoderados banquetes carnales, en los que la comida y la bebida carecerán de modestia, y excederán el modo de los incrédulos. Y esto no pueden creerlo sino los carnales ${ }^{77}$.

Como ya hemos visto para otros autores, el peligro de ver su doctrina entremezclada con heterodoxos manifiesto hizo alejar a Agustín de interpretaciones que podían ser tachadas de materialistas. De este modo, en el De civitate Dei Agustín construye otro edificio interpretativo del pasaje en cuestión:

La Iglesia es, pues, ahora el reino de Cristo y el reino de los cielos. Y al presente reinan con Él también sus santos, cierto que de modo distinto a como reinarán más tarde, pero la cizaña no reina con Él, aunque crezca con el trigo en la Iglesia ${ }^{78}$.

Esta nueva exégesis de Agustín le permite interpretar el pasaje del Apocalipsis del diablo precipitado en el abismo sin contemplar un reinado intrahistórico:

La multitud innumerable de impíos, cuyos corazones son un abismo de malignidad contra la Iglesia de Dios. Y dice que lo precipitó no porque el diablo no estuviera antes allí, sino porque, excluido del corazón de los fieles, comenzó a poseer más fuertemente a los impíos ${ }^{79}$.

El milenio es, en definitiva, una realidad que vive en los corazones de los fieles y coincide con el tiempo de la iglesia peregrina en el mundo. Finalmente, la persecución final de tres años y seis meses será el tiempo del Anticristo, cuya derrota darà lugar al juicio final y a la resurrección de los cuerpos. Hay que decir, de todos modos, que Agustín no excluye la posibilidad de que el juicio final también sea un tiempo que podría coincidir de algún modo con el séptimo día del reino de los santos que apareciá en sus Sermones. En este sentido, no hay que considerar el juicio final como un instante de tiempo infinitesimal sino que es algo que se explaya en el tiempo. Cuando Agustín señala que los santos reinarán de modo distinto con respecto al presente no puede reducirse simplemente a un tiempo extrahistórico sino que la cuestión debería dejarse más bien en suspenso.

77 Agustín de Hipona, La ciudad de Dios, 20.7.1. En Obras completas, 27, pp. 1455-1456 .

78 Ibidem, 20.9.1, p. 1466.

79 Ibidem, 20.7.3, p. 1457. 


\section{Conclusiones}

A través de la reconstrucción de las varias posiciones en los primeros siglos de la Iglesia hemos podido notar una cierta persistencia de posiciones que contemplan un reinado intrahistórico a través de la interpretación del milenio que aparece en Ap, 20. Si exclusimos las posiciones claramente heterodoxas (Cerinto) o con tintes marcadamente carnales, la cuestión de un posible reinado intrahistórico de corte espiritual no ha sido nunca negado por los padres de la Iglesia. También aquellos que parecen más reacios a estas posiciones, como Jerónimo, contemplan la posibilidad de un reinado espiritual. También Agustín, como se ha apuntado al final, a pesar del cambio interpretativo mantiene la posibilidad de un paralelismo entre la septima edad desarrollada en los Sermones y en el periodo del juicio final de La Ciudad de Dios. Lo que siempre se ha negado y considerado ajeno a la Iglesia son las interpretaciones crasamente materialistas; sin embargo, un periodo de plenitud intrahistórico de corte espiritual, más propiamente ecclesial, puede considerarse una doctrina común en el sentir de la Iglesia.

\section{Bibliografía}

Agustín de Hipona, Obras completas, Madrid, 1981.

- La ciudad de Dios

- Sermones

Curti, C., Il regno millenario in Vittorino di Petovio, Augustinianum 18 (1978), 419-433.

Daniélou, J., Teología del judeocristianismo, Madrid 2004.

Diez Macho, A., Apócrifos del Antiguo Testamento, Madrid 1982.

Di Berardino, A., Nuovo dizionario patristico e di antichità cristiane, Genova 2007.

Eusebio de Cesárea, Historia Ecclesiastica, Madrid 2001.

Hipólito, Commentaire sur Daniel, Paris 1947.

Hipólito, El Anticristo, Madrid 2012.

Ireneo de Lyon, Contro le eresie e gli altri scritti, Milano 1997.

Jerónimo de Estridón, Obras completas, Madrid, 1999-2016.

- Comentario a Mateo

- Comentario a Isaías

- Comentario a los profetas menores

- Comentario a Ezequiel

- Comentario al profeta Jeremías

Lactancio, Instituciones divinas, Madrid 1990. 
Martínez Esteban, A., «¿Hipólito milenarista? A propósito de In Danielem IV, 56, 1-7», en: Dos mil años de evangelización: los grandes ciclos evangelizadores, (ed.) E. De La Lama, Pamplona 2001.

Mazzucco, C., Pietrella, E., Il rapporto tra la concezione del millennio dei primi autori cristiani e l'Apocalisse di Giovanni, Augustinianum 18 (1978), 29-45.

Pietras, H., «I prinicipi II, 11 di Origene e il millenarismo», en: Origeniana Octava, (ed.) L. Perrone, Leuven 2003.

Pueyo, J., La plenitud terrena del Reino de Dios en la historia de la teología, Toledo 2020.

Roszak, P. La fe y la participación en la naturaleza divina según santo Tomás de Aquino, Espíritu 155 (2018), 153-172.

Orbe, A., Introducción a la teología de los siglos II y III, Salamanca 1988.

Orbe, A., Teología de San Ireneo, Madrid 1988.

Origenes, I principi, Florencia 1975.

Ruiz Bueno, D., Padres Apostólicos y apologistas griegos, Madrid 2002.

- Carta de Bernabé

- Clemente de Roma, Carta primera a los corintios

- Didaché

- El "Pastor" de Hermas

- Justino, Dialogo con Trifón

Simonetti, M., L'Apocalissi e l'origine del millennio, Vetera Christianorum 24 (1989), 337-350.

Victorino de Petovio, Comentario al Apocalipsis y otros escritos, Madrid 2008. 